VILLULLA, Juan Manuel, Las cosechas son ajenas. Historia de los trabajadores rurales detrás del agronegocio, Editorial Cienflores, Buenos Aires, 2015, 365 páginas.

María Sol FRANSOI

Avances del Cesor, V. XIV, No 16, Primer semestre 2017, pp. 149-152.

ISSNe 2422-6580 / ISSN 1514-3899 - http://web2.rosario-conicet.gov.ar/ojs/index.php/AvancesCesor/index

\title{
VILLULLA, Juan Manuel, Las cosechas son ajenas. Historia de los trabajadores rurales detrás del agronegocio, Editorial Cienflores, Buenos Aires, 2015, 365 páginas
}

María Sol Fransoi

Universidad Nacional de Rosario Centro Núcleo de Estudios del Trabajo y la Conflictividad Social

Juan Manuel Villulla, autor del libro aquí reseñado, realiza un análisis minucioso sobre la situación e historia reciente de los trabajadores rurales pampeanos. En su estudio, Villulla describe el proceso de conformación de este sector obrero, centrando la indagación en las experiencias de aquellos que se encargan, año tras año, de levantar las cosechas de granos.

La publicación de esta obra es resultado de sucesivas instancias de investigación realizadas por el autor durante la elaboración de sus tesis de grado y doctoral. El cuerpo del texto consta de una introducción, diez capítulos y las conclusiones. La información contenida en el mismo resulta de la articulación de etapas de revisión teórica, lectura de antecedentes de la problemática y un intensivo trabajo de campo, que priorizó la realización de entrevistas en profundidad a los trabajadores rurales pampeanos. La recolección de información fue triangulada con el análisis de diferentes fuentes secundarias tales como archivos históricos, censos, estadísticas, mapas, marcos legales $\mathrm{y}$ normativos, panfletos y revistas obreras $\mathrm{y}$ artículos periodísticos.

En la introducción, se realiza una presentación de la problemática abordada y de la estructuración de la investigación, dando cuenta de los propósitos y tópicos centrales en cada apartado del texto. Allí, el autor expresa la importancia de echar luz sobre las condiciones laborales vivenciadas por los trabajadores de la agricultura pampeana, quienes a pesar de erigirse como los "verdaderos productores" de las famosas cosechas récord alcanzadas en las últimas tres décadas, se hayan ampliamente invisibilizados.

En los primeros tres apartados describe el proceso configurativo del asalariado agrícola 
pampeano y en particular la génesis $y$ desarrollo del sector específico que trabaja actualmente en la cosecha de granos, sujeto central de su investigación. Analizando la evolución histórica del conjunto de los trabajadores rurales pampeanos, Villulla identifica cambios significativos en los mecanismos de confrontación desplegados por el movimiento obrero-rural, que se expresan en el pasaje de la efervescencia político-sindical, característica de fines de siglo XIX y principios del XX, a la ausencia generalizada de cualquier tipo de actividad gremial, que signa su cotidianeidad actual. El autor inscribe dichas transformaciones en un complejo proceso histórico a lo largo del cual se modifican las correlaciones de fuerza entre el sector patronal y los trabajadores, en detrimento de estos últimos.

En el capítulo 4, Villulla analiza la distribución de la riqueza entre los trabajadores y los empresarios en la agricultura pampeana a lo largo de la gran expansión económica de los últimos años. Allí explicita cómo entre 1976 y la actualidad, la explotación de los trabajadores aumentó ostensiblemente al profundizarse la brecha entre la rentabilidad agrícola y el salario obrero. En este apartado, describe el proceso por el cual los ingresos de los trabajadores permanecieron prácticamente invariables a pesar del gran boom agrícola de los decenios precedentes, merced a la combinación de diversos factores: el contexto represivo y sus implicancias en el disciplinamiento de la mano de obra, la suspensión sistemática de las conquistas legales, la sanción de un nuevo Régimen Nacional de Trabajo Agrario (RNTA) sumamente regresivo para los trabajadores rurales y la tendencia propatronal que ha adquirido el sindicato que los nuclea.
Además del congelamiento salarial, Villulla presenta en el capítulo 5 otros mecanismos implementados por los empresarios que se orientan a aumentar sus ganancias a costa de los trabajadores. Estas otras modalidades se tornan visibles en el análisis que el autor realiza en torno a las principales transformaciones experimentadas por los procesos productivos agrícolas y su impacto sobre el rol social y económico de los trabajadores. Allí muestra cómo si bien la adopción de nuevas técnicas de producción (la siembra directa, la utilización de semillas transgénicas y de agroquímicos) posibilitó reducir el tiempo de trabajo necesario por hectárea, esto no se tradujo en una mejora en las condiciones laborales. Muy por el contrario, el análisis que nos brinda Villulla manifiesta cómo el sentido en que estas nuevas técnicas son utilizadas por los empresarios implicó, por un lado, una drástica reducción de la demanda de mano de obra y por el otro, la prolongación de la jornada laboral y la intensificación del ritmo de trabajo. Dicho en otras palabras, la forma en que se adoptaron dichas técnicas significó, para muchos obreros, la pérdida de su empleo, y para quienes lograron mantenerlo, un sustancial aumento de su explotación, tanto en términos absolutos como relativos.

En el capítulo 6, la investigación avanza sobre el rol del Estado y la legislación en la adopción de nuevas técnicas orientadas a incrementar la productividad del sector en perjuicio de los trabajadores. Abordando los cambios introducidos en el RNTA bajo la última dictadura militar y analizando cómo dichas modificaciones inciden en la práctica laboral de los obreros, Villulla deja al descubierto la complicidad estatal en la configuración de una nueva etapa de acumulación capitalista en el agro argentino. En efecto, la nueva legislación, no sólo prohibió el derecho a huelga, sino que 
también alentó la intermediación, el pago a destajo y liberó la jornada laboral bajo el argumento de supuestas particularidades del trabajo agrícola vinculadas a factores naturales. Atendiendo a la respuesta obrera ante estas imposiciones, Villulla da cuenta de los reclamos elevados y las frustradas instancias de negociación del sindicato Unión Argentina de Trabajadores Rurales y Estibadores (UATRE) con las entidades patronales que se negaron sistemáticamente a limitar la jornada laboral. Asimismo, explica cómo la desvalorización relativa del salario y el acortamiento de los tiempos de labor obligaron a los trabajadores a adoptar el destajo y el contratismo de servicios como mecanismo o estrategia para lograr su subsistencia, internalizando el ritmo de competencia de sus empleadores.

Otro aspecto que Villulla aborda en su libro, es el impacto de la reducción del tiempo de trabajo por hectárea sobre los patrones de movilidad territorial y su incidencia en la precarización de los trabajadores rurales. Desarrolla este análisis en el séptimo capítulo del libro, donde establece los ciclos de ocupación del asalariado agrícola pampeano a lo largo de su evolución, poniendo de manifiesto cómo las modificaciones en los procesos productivos agrícolas y la reducción de alternativas laborales locales empujan a los trabajadores (incorporados en equipos de contratistas) a recorrer una extensión más amplia de territorio y a trabajar para una mayor cantidad de clientes con el objeto de aumentar el período de empleo, al máximo posible, a fin de lograr su subsistencia.

En el capítulo 8, Villulla analiza cómo la adopción de nuevas técnicas de producción afectó las características tradicionales de los oficios agrícolas y las relaciones sociales generadas en torno a los mismos. Esta metamorfosis se expresa en el pasaje del predominio de los saberes técnicos, que los obreros solían aprender por medio de la práctica y de la transmisión directa desde la infancia, a la primacía del conocimiento digital, que exigió nuevas calificaciones, ajenas a los saberes tradicionales de los obreros rurales, configurando lo que el autor denomina "crisis de la identidad del oficio". Además, Villulla describe cómo la incorporación de esta nueva tecnología posibilitó a la patronal limitar aun más los grados de autonomía obrera sobre los procesos laborales y cómo su adopción contribuyó a reducir los tiempos muertos del proceso productivo.

A pesar de ello, los trabajadores todavía conservan cierta autonomía en el manejo de sus herramientas $y$, en este sentido, Villulla considera importante el análisis de las estrategias patronales orientadas a generar cooperación en el proceso de trabajo, aspecto que desarrolla en el capítulo 9. En una primera instancia, explora cómo el pago a destajo garantiza el involucramiento de los trabajadores en la producción. En segundo lugar, describe cómo operan los compromisos personales construidos entre empleadores y obreros en la cooperación de estos últimos. Finalmente, se detiene específicamente en los dispositivos de vigilancia directa que la patronal utiliza a estos fines en los espacios de trabajo, tales como la designación de un capataz dentro del equipo de trabajo y la existencia de un conjunto de castigos y sanciones (que van desde suspensiones a despidos y difamación) que operan generando temor y que refuerzan aún más la disciplina laboral.

E1 último capítulo del libro versa sobre las modalidades de contestación que los trabajadores rurales han llevado adelante 
bajo las condiciones actuales de apartamiento sindical y aislamiento mutuo, y evalúa las potencialidades que encierran dichas expresiones como prácticas transformadoras y pondera su significado en relación a la construcción de una identidad autónoma de clase. La protesta verbal, los juicios laborales, la propagación de rumores, la rotura deliberada de herramientas, los hurtos a la propiedad del patrón, la renuncia intempestiva durante la cosecha y esporádicos intentos de coordinación de acciones de manera autónoma, constituyen algunas de las experiencias identificadas por Villulla como formas de confrontación adoptadas en el marco de condicionamientos sumamente desfavorables. A pesar de las limitaciones de estas acciones a la hora de transformar la relación de fuerza entre obreros y patrones, Villulla subraya la importancia de las mismas en tanto suponen no sólo un obstáculo a sortear por los empresarios sino que también remiten al carácter siempre activo de los trabajadores ante las contradicciones que encierran las relaciones asalariadas.

Para finalizar, en las conclusiones del libro, Villulla sostiene que uno de los aportes más significativos de su estudio, consiste en poner en evidencia las fuertes tensiones existentes entre el capital y el trabajo detrás del agronegocio y en mostrar los elevados índices de explotación de la mano de obra sobre los que descansa el boom de la producción de granos de las últimas décadas.

Cabe agregar que su estudio brinda un valioso aporte al campo de la sociología del trabajo en tanto contribuye a profundizar el conocimiento en torno a la génesis y desarrollo del colectivo de trabajadores vinculado a uno de los sectores más importantes de la economía argentina, como lo es el agro pampeano. 